\title{
COLOURS IN PAINTING (CHITRKALA ME RANG)
}

\author{
Kiran Dhiman (Research scholar) \\ Jiwaji University, Gwalior
}

Colours are life of paintings. Without colours 'painting' seems incomplete and dull. Painting is visual expression, which is made combining two basic elements 'drawing' and 'colouring'. Colours add the charm to an artwork. Monochrome shade is also having its own value but colours make it more appealing and lively.

Since the upper paleolithic prehistoric times human being practice 'art' specially paintings in rock shelting to express their thoughts, which means it was a mode of communication from the beginning. This art creates, for the viewer, a degree of experiential contact with prehistoric art. It provides the basis for entering into the changing aspects of the living arts of man. It is beleived that man's awareness of the world around came through this primeval sense of sight and sound. These two sense have stimulated

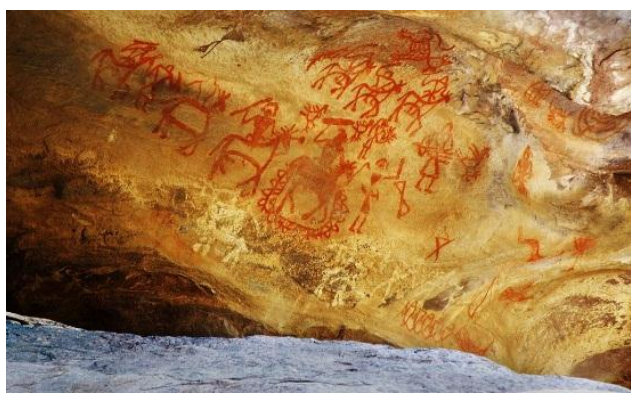
artists' expressions visual and aural in the prehistoric past as well as in the contemporary cultures. From this prehistoric times human being practice 'art' to express their thoughts, which means it was a mode of communication from the beginning. Colours also have meanings to convey. At that time human beings did not have any academic skill or special training but it was so spontaneous and natural that simplicity brings the beauty. Those little touch of colours made those masterpiece paintings or drawings that have been placed onto the rock face. Cave dwellers of prehistoric time used minimum colours whichever were available in nature directly. Rock paintings have been made with mineral earths and other natural compounds found across much of the world. The predominantly used colours are red, black, pale yellow and white. Red paint is usually attained through the use of ground ochre, while black paint is typically composed of charcoal, or sometimes from minerals such as manganese. White paint is usually created from natural chalk, kaolinite clay or diatomaceous earth. Once the pigments had been obtained, they would be ground and mixed with a liquid, such as water, blood, urine, or egg yolk, and then applied to the stone as paint using a brush, fingers, or a stamp. Alternately, the pigment could have been applied on dry, such as with a stick of charcoal. In some societies, the paint itself has symbolic and religious meaning.

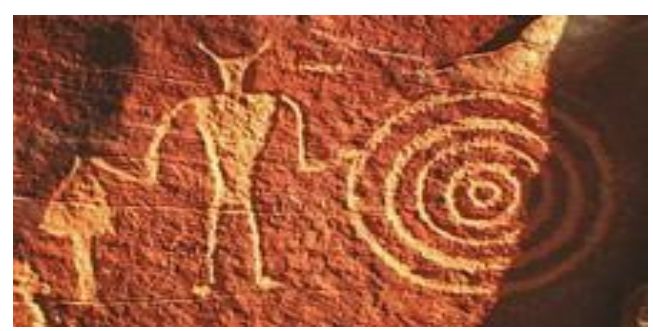

Handprint an unusual form, found in many places, although not in all rock-art producing cultures. There are three forms of this; the first involves covering the hand in wet paint and then applying it to the rock. The second involves a design being painted onto the hand, which is then in turn added to the surface. The third involves the hand first being placed against the panel, with dry paint 
then being blown onto it through a tube, in a process that is like spray-painting. The resulting image is a negative print of the hand.

Then we find paintings from oldest civilizations around the world like China, Egypt, Mesopotamia and Harappan (Indus) civilization, where we find use of colours elaborately. By this time importance of colours have been realized by all communities.

In ancient Egypt, colour was integral part of everything in life. In art, colours were clues to the nature of beings depicted in the work. The Egyptian artist had used mainly six colours including black and white. These colours were generated mostly from minerals from nature which is everlasting and each colours had a symbolic meaning; for instance Green was the colour of vegetation and new life, Red was the colour of life and victory and yellow was for eternal because the sun and the gold are yellow.

In traditional Chinese art and culture, black, red, white and yellow are viewed as standard colors. These colors correspond to the five elements of water, fire, wood, metal and earth.In china Yellow, corresponding with earth, considered the most beautiful and prestigious color. There is a Chinese saying that 'Yellow generates Yin and Yang', implies that yellow is the center of everything. Yellow also signifies to them neutrality, heroism and good luck. Yellow is sometimes paired with red in place of gold. Here is a painting from Ming Dynasty. Here is an example of ancient Chinese painting with dominating yellow colour

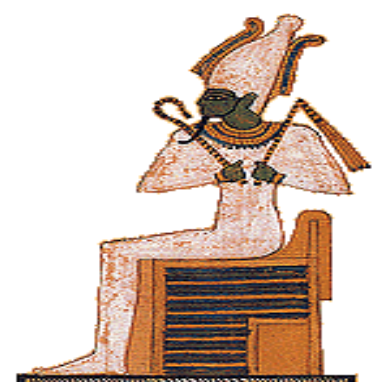
background.

In Mesopotamia art was important part of life. Every home was having statues made of terracotta, gypsum, stone, or copper. Almost all of such sculptures show a person standing silently with their hands clasped in prayer. The Standard of Ur, is one of the most famous Mesopotamian Mosaics we have, which was found by Leonard Woolley during excavations of the royal tombs at Ur, in the year 1922. The Standard of Ur takes the place of a flag as we use it today; a standard is what is used to represent king or Country. The Standard of Ur is constructed of two small rectangular wooden panels that are in laid with mother-of-pearl, mussel shells, and lapis lazuli. Mosaics are often used to tell a story, and this one is no different. It shows scenes of war on one side, and other sideshows scenes from a banquet or victory feast.

Standard of Ur

The battle side depicts soldiers bringing prisoners of war back to their kind, some people are riding four-wheeled chariots. This picture is the earliest evidence we have of the use of the wheel.

Various kinds of paintings like wall paintings, pottery paintings, and paintings on woodpanal or leather from these

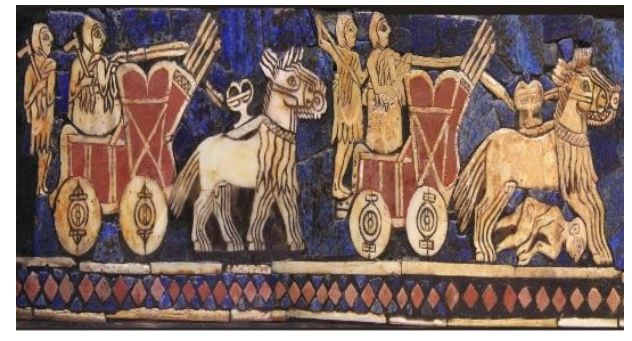


early civilizations show how artists and artisans used colours in many ways and gradually invented suitable techniques for applications and its effects. Basic ingredients of colours are always collected from nature in case of every part of the world but applications, effects and choice of coloursdiffer place to place.

Pottery art flourished in China and Indus valleyin a massive way and Wall painting, painting wood etc. found mostly in Egypt and Mesopotamia. In fact painted pottery is one of the main attribute in Mesopotamia also. So colours became integral part of artwork even before Christ era around the world.

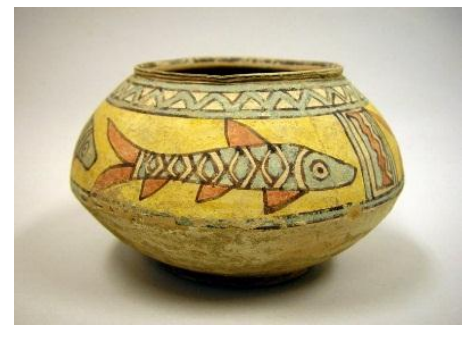

Painted pottery of Harappan civilization is great example of human creativity, which combines drawing and colouring in beautiful way to represent the ideas. One of the examples is here that shows skillful application of very limited colour shades to make a daily-life object so attractive. Colourful paintings bring a rich feeling in any creative object and give a finished look as a whole.Thesepotteries were generally painted before firing, so that in the process of firing the paint adhered to the surface and attained durability. The colour of the paint sometimes varied due to varying temperatures during firing. The pigments used for this, and the color and treatment of the background, for example, are factors of lesser constancy and must concern us less than the designs. There is no need to point out the several examples in Mesopotamia and Iran of the persistence of early elements of painted pottery design into successively later periods, each of them differing as to pigments and background. Vedic age pottery also no different about experimenting colours and designs.

Ajanta cave/wall paintings are best example for colour application inancient India. Buddhist monks created 16 cave walls in unique method with spectacle carving work as well as paintings stories from Jataka and Buddha's life religiously. Soothing colours prepared from stones and minerals mixed with suitable binder they have used to make those tempera paintings.

The bright natural colours made these cave paintings most beautiful and scholars from around the world researched again and again finding new aspect about the techniques they have applied.

Ajanta painting

Through the ages human being progressed and created innovative artworks in several techniques.Colours have been significant for art and artists immensely for its meaning, theme to represent, brighter impact and a pleasurable work process. Human being loves to experiment and explore; so experimenting with coloursalong with various methods and materials gave magical result to the artwork made by different people. Actually there are unlimited ways to apply colours and techniques on painting. So many years several artists are working in different places around the world but skill there can be new ways to be found. Colour has a versatile approach when we apply on paintings.

Modern painters even playing with digital colours to express their thoughts, taking more challenge to create unique things. So Coloursare indispensable factor of painting process in past present and future of human creativity and experimentation with available colours they have.

Modern handmade oil painting 